\title{
IGF2BP2 rs11705701 polymorphisms are associated with prediabetes in a Chinese population: A population-based case-control study
}

\author{
LIYUAN HAN $^{1 *}$, YUANYUAN LI $^{2 *}$, LINLIN TANG $^{1 *}$, ZHONGWEI CHEN $^{3}$, TAO ZHANG $^{3}$, SIHAN CHEN $^{3}$, \\ SHENGYUAN LIU ${ }^{3}$, XIAOLIN PENG ${ }^{3}$, YIFENG MAI ${ }^{4}$, RENJIE ZHUO ${ }^{1}$, CHANGYI WANG $^{3}$ and SHIWEI DUAN ${ }^{1}$ \\ ${ }^{1}$ Zhejiang Provincial Key Laboratory of Pathophysiology, School of Medicine, Ningbo University, \\ Ningbo, Zhejiang 315211; ${ }^{2}$ Key Laboratory of Etiology and Epidemiology, Center for Endemic Disease Control, \\ Chinese Center for Disease Control and Prevention, Harbin Medical University, Harbin, Heilongjiang 150081; \\ ${ }^{3}$ Shenzhen Nanshan Center for Chronic Disease Control, Shenzhen, Guangdong 518054; ${ }^{4}$ Department of Endocrinology, \\ The Affiliated Hospital of Ningbo Medical School, Ningbo University, Ningbo, Zhejiang 315000, P.R. China
}

Received January 23, 2015; Accepted March 1, 2016

DOI: $10.3892 /$ etm.2016.3554

\begin{abstract}
Associations between insulin-like growth factor 2 mRNA-binding protein 2 (IGF2BP2) rs11705701, insulin receptor substrate 1 rs7578326, gastric inhibitory polypeptide receptor rs10423928 and transcription factor 7-like 2 rs12255372 gene polymorphisms with prediabetes and type 2 diabetes (T2D) have not been evaluated in the Han Chinese population. These four genetic variants were investigated for their associations with prediabetes and T2D among 490 unrelated patients with T2D, 471 patients with prediabetes and 575 healthy controls. Sequenom MassARRAY software was used to genotype the patients for these variants. The Generalized Multifactor Dimensionality Reduction method was used to analyze the gene-gene and gene-environment interactions. A breakdown analysis by gender revealed a significant association of $I G F 2 B P 2$ rs11705701 with prediabetes under the dominant genetic model in females following application of the Bonferroni correction (odds ratio $=0.26$; $95 \%$ confidence interval $=0.10-0.67 ; \mathrm{P}=0.005)$. However, no significant associations were reported between any of the other three polymorphisms and T2D under any genetic models.
\end{abstract}

Correspondence to: Professor Shiwei Duan, Zhejiang Provincial Key Laboratory of Pathophysiology, School of Medicine, Ningbo University, 818 Fenghua Road, Ningbo, Zhejiang 315211, P.R. China E-mail: duanshiwei@nbu.edu.cn

Mr. Changyi Wang, Shenzhen Nanshan Center for Chronic Disease Control, 7 Huaming Road, Shenzhen, Guangdong 518054, P.R. China E-mail: wangchangyi2002@163.com

\section{*Contributed equally}

Key words: type 2 diabetes, prediabetes, insulin-like growth factor 2 mRNA-binding protein 2, insulin receptor substrate 1 , gastric inhibitory polypeptide receptor, transcription factor 7-like 2
Furthermore, there were no statistically significant gene-gene or gene-environment interactions when evaluated with the above association tests. The present case-control study reveals a significant association between IGF2BP2 rs11705701 and prediabetes in female patients.

\section{Introduction}

Type 2 diabetes (T2D) is a complex disease that is affected by genetic and environmental factors, and their interactions. The prevalence of diabetes has increased substantially in China due to the changes of lifestyle (mainly overnutrition and lack of physical activity) (1). In a representative sample of Chinese adults in 2013, the incidence of diabetes and prediabetes was reported to be $11.6 \%$ and $50.1 \%$ respectively, which accounted for 113.9 million patients with diabetes and 493.4 million patients with prediabetes (2).

Insulin-like growth factor 2 mRNA-binding protein 2 (IGF2BP2) is a member of the IGF2 mRNA-binding protein family (2). $I G F 2 B P 2$ is located on chromosome $3 \mathrm{q} 27$ and is involved in embryogenesis and pancreatic development (3). Furthermore, IGF2BP2 can adjust transcription of IGF2, which in turn is involved in the development of insulin function (4). Insulin receptor substrate 1 (IRS1) is an early mediator in the insulin-stimulated signal transduction pathway (5). Experiments in IRS1 knockout mice have demonstrated that IRSI is an essential contributor to insulin activity in skeletal muscle, adipose tissue and pancreatic $\beta$-cells (6), and IRSI has therefore been hypothesized to be a diabetes susceptibility gene (7). GIPR encodes gastric inhibitory polypeptide receptor (GIPR), which is capable of inducing insulin response following an oral glucose challenge (8). GIPR is expressed in the pancreas and in adipocytes (9), and it is important in the regulation of insulin secretion. The transcription factor 7-like 2 (TCF 7L2) gene spans $215.9 \mathrm{~kb}$ on chromosome 10q25, and is the most recognized T2D susceptibility gene. TCF7L2 encodes a transcription factor implicated in Wnt signaling and proglucagon transcription (10). A previous study reported that TCF 72 
increases susceptibility to T2D through a reduction in blood glucose induced by insulin secretion (11).

All the aforementioned genes have significant roles in insulin function and signaling. However, little is known with regard to the associations between the IGF2BP2 rs11705701, IRS1 rs7578326, GIPR rs10423928 and TCF7L2 rs12255372 polymorphisms and T2D or prediabetes in the Chinese population. In the present study, the potential associations of IGF2BP2 rs11705701, IRS1 rs7578326, GIPR rs10423928 and TCF7L2 rs12255372 with prediabetes and T2D were investigated in a Chinese population. Furthermore, a gene-gene and gene-environmental interaction analysis was conducted, as prediabetes and T2D are complex disorders affected by genetic and environmental factors and their interactions.

\section{Materials and methods}

Subjects. The present study included 490 unrelated patients with T2D [242 males and 248 females; mean age, $62.76 \pm 11.14$ years; mean body mass index (BMI), $24.95 \pm 3.46 \mathrm{~kg} / \mathrm{m}^{2}$ ], 471 patients with prediabetes (230 males and 241 females; mean age, $61.39 \pm 11.43$ years; mean BMI, $25.28 \pm 3.82 \mathrm{~kg} / \mathrm{m}^{2}$ ) and 575 healthy control patients (286 males and 289 females; mean age, 57.94 \pm 10.81 years; mean BMI, $23.52 \pm 3.17 \mathrm{~kg} / \mathrm{m}^{2}$ ). T2D and prediabetes were diagnosed in accordance with the criteria of the American Diabetes Association guidelines, 2010 (12). All the participants were Han Chinese patients of 16 community health service centers in the Nanshan district of Shenzhen (China). A two-stage sampling method (involving, the use of computer-generated sampling to select 16 communities in the initial stage, followed by convenience sampling was used to determine eligible subjects in the second stage) and a procedure utilizing computer-generated random numbers were used. The inclusion criteria was as follows: i) Local residents who had lived in Shenzhen for $\geq 6$ months; ii) standard clinical criteria (American Diabetes Association guidelines, 2010 (12) were applied with regard to prediabetes and T2D diagnosis, while the healthy controls were selected based on fasting blood glucose levels $<6.1 \mathrm{mmol} / 1$. Exclusion criteria included patients with hypertension, cancer, severe liver and kidney disease, or pregnancy. Written informed consent was obtained from all subjects. The present study was approved by the Ethical Committee of the Shenzhen Nanshan Center for Chronic Disease Control (Shenzhen, China).

Genotyping. Blood samples $(5 \mathrm{ml})$ were collected imediately the morning following an overnight fast in ethylenediaminetetraacetic acid-containing collection tubes. DNA was isolated from peripheral blood lymphocytes using a Lab-Aid 820 Automated Blood DNA Extraction system (Zeesan Biotech, Xiamen, China). Genotyping was performed using the MassARRAY iPLEX system (Sequenom, San Diego, CA, USA) according to the manufacturers' protocol. Primers for the polymerase chain reaction (PCR) and single base extension were designed using Sequenom software (PyroMark Assay Design software; version 2.0.1.15; Qiagen $\mathrm{GmbH}$, Hilden, Germany). In the present study, primer extension for genotyping was performed on the Sequenom MassARRAY iPLEX platform. In the primer extension, $\mathrm{ddH}_{2} \mathrm{O}, 10 \mathrm{X}$
Buffer, $25 \mathrm{mM}$ dNTP, $25 \mathrm{mM} \mathrm{MgCl}_{2}, 0.5 \mu \mathrm{M}$ Primer, PCR enzyme and DNA template were used in the PCR reaction system. After purifying the products and transferring to SpectroCHIP, MALDI-TOF mass spectrometry was used for SNP genotyping. Thermocycling was carried out under the following conditions: Initial denaturation, $94^{\circ} \mathrm{C}$ for $15 \mathrm{sec}$ followed by 45 cycles at $94^{\circ} \mathrm{C}$ for $20 \mathrm{sec}$ (denaturation), $56^{\circ} \mathrm{C}$ for $30 \mathrm{sec}$ (annealing), and $72^{\circ} \mathrm{C}$ for $1 \mathrm{~min}$ (extension), with a final extension step at $72^{\circ} \mathrm{C}$ for $3 \mathrm{~min}$. The primer sequences are reported in Table I, and the characteristics of the study subjects are reported in Table II.

Statistical analysis. Data are expressed as the mean \pm standard deviation for continuous variables. Comparisons among the three groups for continuous variables were performed using one-way analyses of variance. Deviation from the Hardy-Weinberg equilibrium was assessed by $\chi^{2}$ test. Binary logistic regression analysis was performed to calculate odds ratios (ORs) and 95\% confidence intervals (CIs) subsequent to adjusting for age and BMI. The genetic models tested in the present study included additive, dominant and recessive models. Bonferroni correction was applied to determine the significance thresholds. As a result, $\mathrm{P}<0.006$ was adopted as the threshold of significance (Tables III and IV).

All data were analyzed using SPSS version 17.0 software (SPSS, Inc., Chicago, IL, USA). A power analysis was performed with the Power and Sample Size Calculation software (version 3.0.43) (13). Generalized multifactor dimensionality reduction (GMDR; www.ssg.uab.edu/gmdr) was applied to analyze the potential gene-gene and gene-environment interactions. A number of parameters, including testing balance accuracy (TBA), cross-validation consistency (CVC) and sign test P-value were obtained. The model with the maximum TBA, the maximum CVC and a sign test P-value of $<0.05$ were considered to represent the best model.

\section{Results}

Characteristics of subjects. The characteristics of the study subjects are reported in Table II. There were significant differences in the age and BMI of the control patients and patients with prediabetes or T2D $(\mathrm{P}=0.001)$, although differences between these two groups were not significant $(\mathrm{P}=0.055$ and 0.143 , respectively).

Association between the four SNPs and prediabetes and T2D. The allele and genotype frequencies of the four SNPs in the whole study cohort are summarized in Table III. Association of these genotypic variants with prediabetes or T2D was performed using logistic regression, subsequent to adjusting for age and BMI, in association with additive, dominant and recessive genetic models. The genotype distribution of rs11705701 in the IGF2B15P2 gene, rs7578326 in the IRS1 gene, rs10423928 in the GIPR gene and rs12255372 in the TCF7L2 gene among the three groups corresponded with the HWE. None of these SNPs had a significant allelic or genotypic association with T2D. The ORs and 95\% CIs for IGF $2 B P 2$ rs11705701 with prediabetes in the additive and dominant models were $(\mathrm{OR}=0.79 ; 95 \% \mathrm{CI}=0.63-0.98 ; \mathrm{P}=0.03)$ and $(\mathrm{OR}=0.44 ; 95 \% \mathrm{CI}=0.23-0.83 ; \mathrm{P}=0.01)$ respectively 
Table I. Primer sequences used for genotyping.

\begin{tabular}{lcc}
\hline Gene/SNP & PCR round & Primer sequence $\left(5^{\prime}-3^{\prime}\right)$ \\
\hline$I G F 2 B P 2$ & First & ACGTTGGATGTGATGGTTAGAGCCTGGTCC \\
rs 11705701 & Second & ACGTTGGATGGCTTGGAATCTTCTTCTGCC \\
$I R S 1$ & First & ACGTTGGATGGATTTCCGTTGGTGACACAG \\
rs7578326 & Second & ACGTTGGATGTCTGACATGTGGCACTTTAC \\
GIPR & First & ACGTTGGATGGGAAAATACTAGTCTCAGTGG \\
rs 10423928 & Second & ACGTTGGATGCTTAGCATATACACATGCTC \\
$T C F 7 L 2$ & First & ACGTTGGATGGAGTGTGCATTAAAGCTTGG \\
rs12255372 & Second & ACGTTGGATGAGGTATAGTTCTCCTGGTCC
\end{tabular}

PCR, polymerase chain reaction; SNP, single nucleotide polymorphism; IGF2BP2, insulin-like growth factor 2 mRNA-binding protein 2; IRS1, insulin receptor substrate 1; GIPR, gastric inhibitory polypeptide receptor; TCF7L2, transcription factor 7-like 2.

Table II. Characteristics of the subjects included in the present study.

\begin{tabular}{|c|c|c|c|c|c|c|}
\hline Category & Controls & Prediabetes & Type 2 diabetes & $\mathrm{P} 1$ & $\mathrm{P} 2$ & P3 \\
\hline Total subjects (n) & 575 & 471 & 490 & & & \\
\hline Female/male (n) & $289 / 286$ & $241 / 230$ & $248 / 242$ & 0.812 & 0.915 & 0.953 \\
\hline Age (years) & $57.94 \pm 10.81$ & $61.39 \pm 11.43$ & $62.76 \pm 11.14$ & $0.001^{\mathrm{a}}$ & 0.055 & $0.001^{\mathrm{a}}$ \\
\hline BMI (kg/m²) & $23.52 \pm 3.17$ & $25.28 \pm 3.82$ & $24.95 \pm 3.46$ & $0.001^{\mathrm{a}}$ & 0.143 & $0.001^{\mathrm{a}}$ \\
\hline \multicolumn{7}{|l|}{ Female } \\
\hline Age (years) & $58.50 \pm 10.00$ & $61.66 \pm 10.43$ & $63.99 \pm 10.28$ & $0.001^{\mathrm{a}}$ & $0.012^{\mathrm{a}}$ & $0.001^{\mathrm{a}}$ \\
\hline BMI $\left(\mathrm{kg} / \mathrm{m}^{2}\right)$ & $23.18 \pm 3.09$ & $25.18 \pm 4.04$ & $24.69 \pm 3.58$ & $0.001^{\mathrm{a}}$ & 0.123 & $0.001^{\mathrm{a}}$ \\
\hline \multicolumn{7}{|l|}{ Male } \\
\hline Age (years) & $57.38 \pm 11.56$ & $61.10 \pm 12.42$ & $61.51 \pm 11.85$ & $0.001^{\mathrm{a}}$ & 0.708 & $0.001^{\mathrm{a}}$ \\
\hline BMI (kg/m²) & $23.87 \pm 3.22$ & $25.37 \pm 3.59$ & $25.20 \pm 3.32$ & $0.001^{\mathrm{a}}$ & 0.595 & $0.001^{\mathrm{a}}$ \\
\hline
\end{tabular}

Groups were compared using one-way analysis of variance. P-values: P1, P-value of the patients with prediabetes vs. the controls; P2, P-value of the patients with type 2 diabetes vs. those with prediabetes; P3, P-value of the patients with type 2 diabetes vs. the controls. BMI, body mass index.

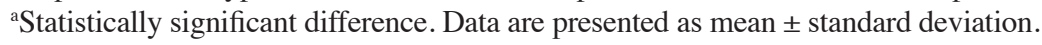

(Table III). However, these were not concluded to be significant following application of the Bonferroni correction.

The allele and genotype frequencies of the four SNPs separated by gender are reported in Table IV. IGF2BP2 rs11705701 was associated with female patients with pre-diabetes to a greater degree than female T2D and control patients, under the dominant model following application of the Bonferroni correction $(\mathrm{OR}=0.26,95 \% \mathrm{CI}=0.10-0.67, \mathrm{P}=0.005)$. No significant association was observed between the other three SNPs and prediabetes in the present study. In addition, associations between the four SNPs and prediabetes and T2D in females and males. According to power calculations, the present sample size provided $52.3 \%$ power $(\partial=0.05)$ to detect a significant association of rs11705701 with prediabetes.

Gene-gene and gene-environmental interactions. The potential gene-gene and gene-environmental interactions were then investigated. As shown in Table V, the interaction model between IGF2BP2 rs11705701, IRS1 rs7578326, GIPR rs10423928 and TCF7L2 rs12255372 was the best model to detect gene-gene interactions between patients with T2D and control patients, with a maximum TBA of 54.5\%. However, the value of TBA was not higher than $60 \%$, despite the sign test $\mathrm{P}$-value being $<0.05$; this gene-gene interaction model was therefore not considered to be robust and reliable. No significant gene-environment interactions were identified when comparing patients with prediabetes or T2D and control patients.

\section{Discussion}

In the present study, the association between IGF2BP2 rs11705701, IRS1 rs7578326, GIPR rs10423928 and TCF7L2 rs12255372 polymorphisms were analyzed in an independent case-control sample. The results suggested a significant association between IGF2BP2 rs11705701 and prediabetes in females. No statistically significant gene-gene and gene-environment interactions were observed. To the best of our knowledge, this is the first study to report an association between IGF $2 B P 2$ rs11705701 and prediabetes in the Han Chinese population.

No statistically significant associations were identified between rs11705701 and T2D susceptibility in the whole and 


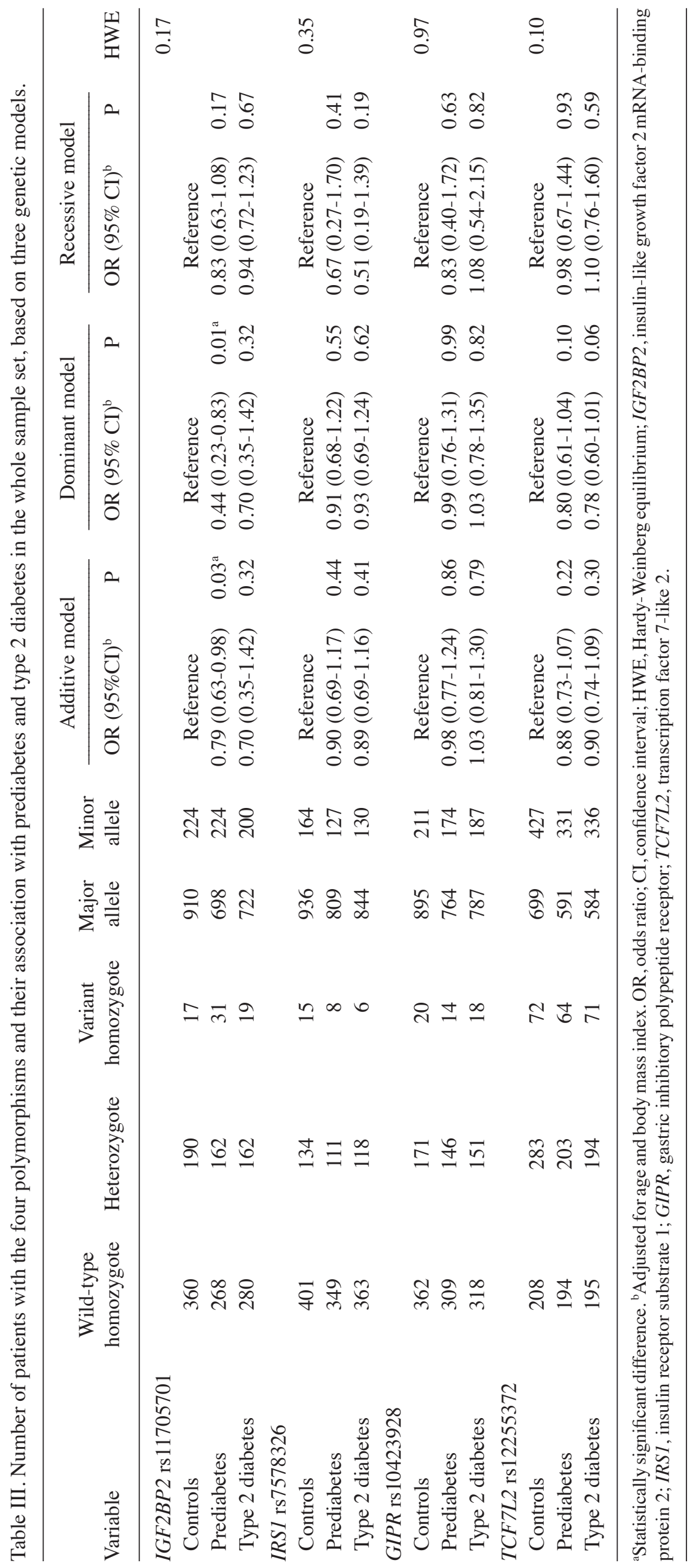




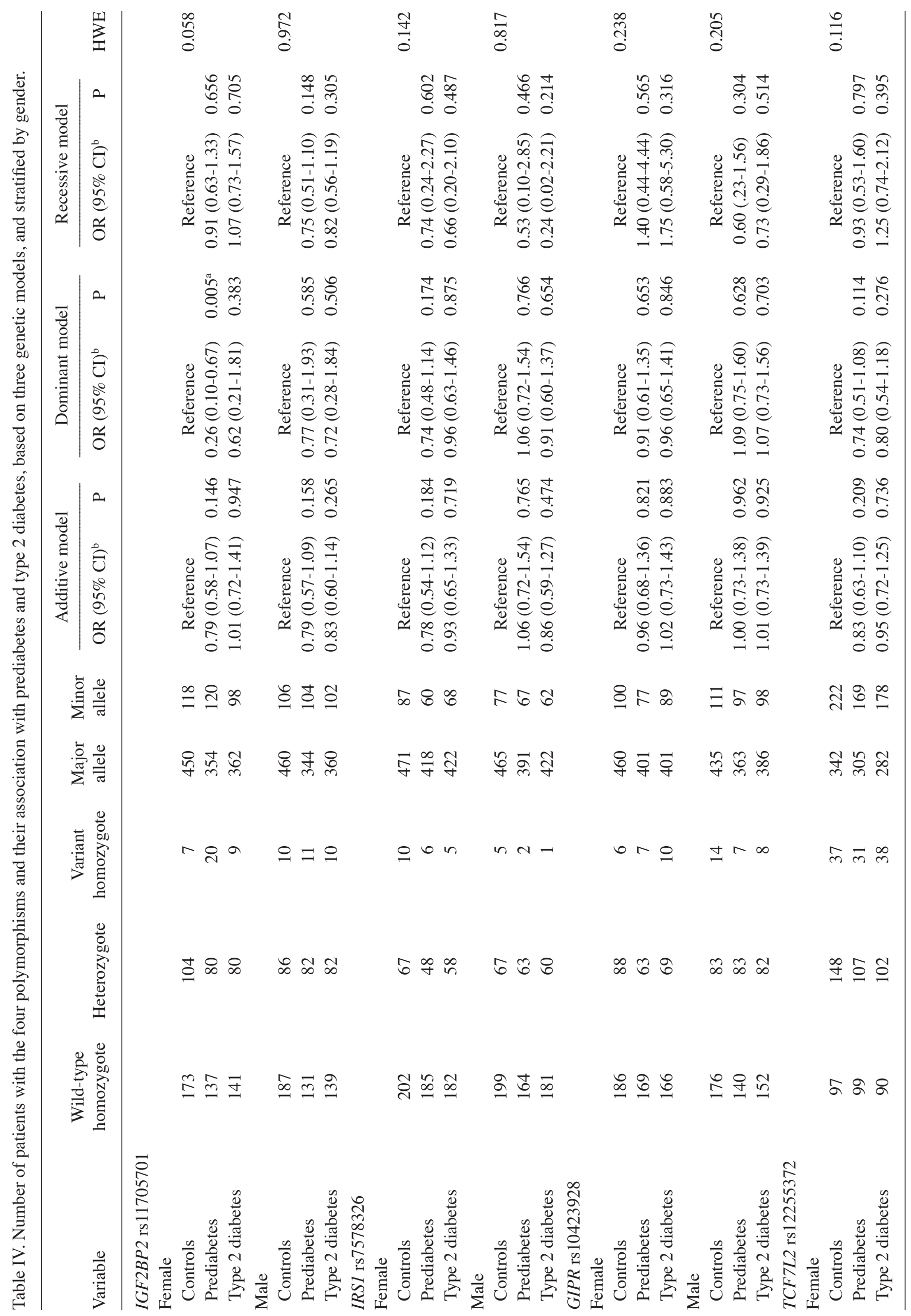


subgroup analyses. However, Chistiakov et al (14) reported that the rs11705701-A allele was associated with higher T2D risk in a Russian population. Similarly, Li et al (15) suggested that rs11705701 had secondary effects on insulin resistance and $\beta$-cell function, thereby contributing to T2D risk in Mexican Americans. The allele frequencies of rs11705701 therefore differed among populations. For example, the minor allele frequency was 0.38 in a Russian population and 0.33 in a sample of Mexican Americans, but was 0.21 in the current study. The discrepancies among studies may be due to the variation of minor allele frequencies in the different ethnic populations.

A genome-wide study reported that $I G F 2 B P 2$ gene polymorphisms were associated with increased T2D risk (16). The most widely studied polymorphism of IGF2BP2 gene is rs4402960, which has previously been investigated in numerous populations with contradictory results (17-19). Wu et al (20) performed the most comprehensive meta-analysis of 35 studies with 175,965 subjects for the two widely studied IFG2BP2 polymorphisms, rs4402960 and rs1470579. This previous study demonstrated that $I G F 2 B P 2$ polymorphisms were significantly associated with increased risk of T2D, particularly in East Asian and Caucasian populations (20). It has also been reported that the rs11705701 and rs4402960 polymorphisms were in marked linkage disequilibrium (LD) in Mexican Americans; however, only rs4402960 contributed to T2D risk, which indicated that rs11705701 may be in LD with a causal variant, with functional consequences for IGF2BP2 in Mexican Americans (15).

$\mathrm{T} 2 \mathrm{D}$ and prediabetes are complex disorders that may have an etiology in the interactions between multiple genes or environmental factors. The present study used a gene-gene and gene-environmental analysis to determine the presence of interactions among the tested variants and clinical parameters. No statistically significant and robust interactions were observed between these polymorphisms and the analyzed clinical parameters, however, BMI and age were identified as the most significant factors for the development of prediabetes and T2D, respectively.

Notably, the present study failed to replicate the associations of IRS1 rs7578326, GIPR rs10423928 and TCF7L2 rs12255372 with prediabetes and T2D in the Chinese population. This is in contrast to the study by Sonestedt et al (21), which demonstrated that the GIPR rs10423928 modified T2D risk by affecting dietary composition. A meta-analysis of nine genome-wide association studies suggested that the rs10423928-A allele increased T2D risk in corroborating studies $(35,689$ cases and 89,798 control patients) (22). A previous genome-wide association study demonstrated that the IRSI rs7578326 polymorphism contributed to T2D susceptibility in European populations (23). In addition, the TCF7L2 rs12255372 was identified to be significantly associated with T2D (24), but a meta-analysis revealed no significant effect of rs12255372 on T2D risk in a Han Chinese population (25). The contradictory results between studies may be attributed to multiple factors, including different sample size, diverse genetic backgrounds, differing environmental factors and inclusion criteria.

In the current study, strict inclusion and exclusion criteria of sample collection were applied in a homogeneous population in order to reduce sample bias, which strengthened the validity of the study. Furthermore, the potential gene-gene and 
Table V. Gene-gene and gene-environment interaction analysis by generalized multi-factor dimensionality reduction.

\begin{tabular}{|c|c|c|c|}
\hline Model & $\begin{array}{c}\text { Testing balance } \\
\text { accuracy }\end{array}$ & $\begin{array}{l}\text { Sign } \\
\text { test }\end{array}$ & $\begin{array}{c}\text { Cross-validation } \\
\text { consistency }\end{array}$ \\
\hline \multicolumn{4}{|l|}{ Prediabetes vs. controls } \\
\hline \multicolumn{4}{|l|}{ Gene-environment interactions } \\
\hline BMI & 0.602 & 0.001 & $10 / 10$ \\
\hline BMI, rs 7578326 & 0.608 & 0.001 & $6 / 10$ \\
\hline BMI, rs11705701, rs7578326 & 0.596 & 0.001 & $6 / 10$ \\
\hline Age, BMI, rs11705701, rs7578326 & 0.605 & 0.001 & $9 / 10$ \\
\hline Gender, BMI, rs11705701, rs12255372, rs7578326 & 0.559 & 0.001 & $10 / 10$ \\
\hline Gender, age, BMI, rs11705701, rs12255372, rs7578326 & 0.603 & 0.001 & $10 / 10$ \\
\hline Gender, age, BMI, rs11705701, rs12255372, rs7578326, rs10423928 & 0.564 & 0.015 & $10 / 10$ \\
\hline \multicolumn{4}{|l|}{ Gene-gene interactions } \\
\hline rs 12255372 & 0.509 & 0.178 & $7 / 10$ \\
\hline rs 11705701, rs 12255372 & 0.494 & 0.623 & $6 / 10$ \\
\hline rs 11705701, rs 12255372, rs 7578326 & 0.515 & 0.175 & $8 / 10$ \\
\hline rs 11705701, rs 12255372, rs 7578326, rs 10423928 & 0.523 & 0.054 & $10 / 10$ \\
\hline \multicolumn{4}{|l|}{ Type 2 diabetes vs. controls } \\
\hline \multicolumn{4}{|l|}{ Gene-environment interactions } \\
\hline Age & 0.591 & 0.001 & $10 / 10$ \\
\hline Age, rs 11705701 & 0.595 & 0.001 & $5 / 10$ \\
\hline Age, BMI, rs 12255372 & 0.613 & 0.001 & $9 / 10$ \\
\hline Age, BMI, rs12255372, rs10423928 & 0.604 & 0.001 & $9 / 10$ \\
\hline Age, BMI, rs11705701, rs12255372, rs10423928 & 0.582 & 0.001 & $8 / 10$ \\
\hline Gender, age, BMI, rs11705701, rs12255372, rs 10423928 & 0.583 & 0.001 & $7 / 10$ \\
\hline Gender, age, BMI, rs11705701, rs12255372, rs7578326, rs10423928 & 0.554 & 0.001 & $10 / 10$ \\
\hline \multicolumn{4}{|l|}{ Gene-gene interactions } \\
\hline rs12255372 & 0.532 & 0.054 & $10 / 10$ \\
\hline rs 12255372, rs 10423928 & 0.543 & 0.015 & $9 / 10$ \\
\hline rs 12255372, rs 7578326, rs 10423928 & 0.515 & 0.054 & $4 / 10$ \\
\hline rs11705701, rs12255372, rs7578326, rs 10423928 & 0.548 & 0.001 & $10 / 10$ \\
\hline
\end{tabular}

BMI, body mass index.

gene-environmental interactions were evaluated using GMDR. GMDR is appropriate to both dichotomous and quantitative phenotypes that allow adjustment for covariates in population-based studies (26) However, there were also limitations to the present study: It is well-established that diabetes is affected by numerous factors, but the confounding factors included in the current study were limited.

In conclusion, the present results indicated that $I G F 2 B P 2$ rs11705701 may have a significant association with prediabetes in females. However, additional studies with larger sample sizes are required to confirm these findings. Functional studies are essential to investigate whether the $I G F 2 B P 2$ rs11705701 works independently or in combination with other genes.

\section{Acknowledgements}

The present study was supported by grants from the National Natural Science Foundation of China (grant nos. 81373094 and 81402745), the Natural Science Foundation of Ningbo City (grant no. 2011A610037), Ningbo Social Development Research Projects (grant nos. 2014C50051 and 2014A610268), the Key Program of Education Commission of Zhejiang Province (grant no. Z201017918), the Natural Science Foundation of Zhejiang Province (grant nos. LR13H020003 and LQ13H260002), Zhejiang Province Scientific Research Projects of Education (grant no. Y201326971), the Ministry of Education, Humanities and Social Sciences project (grant no. 14YJC630046), the Scientific Research Fund of Ningbo University (grant no. xk11349) and the Ningbo University Talent Project (grant no. ZX2012000046). We would like to thank the participants, doctors and nurses in the community health centers for their involvement in the data and sample collection.

\section{References}

1. Yan L, Xu MT, Yuan L, Chen B, Xu ZR, Guo QH, Li Q, Duan Y, Huang Fu , Wang YJ, et al: Prevalence of dyslipidemia and its control in type 2 diabetes: A multicenter study in endocrinology clinics of China. J Clin Lipidol 10: 150-160, 2016. 
2. Xu Y, Wang L, He J, Bi Y,Li M, Wang T, Wang L, Jiang Y, Dai M, $\mathrm{Lu}$ J, et al; 2010 China Noncommunicable Disease Surveillance Group: Prevalence and control of diabetes in Chinese adults. JAMA 310: 948-959, 2013.

3. Christiansen J, Kolte AM, Hansen Tv and Nielsen FC: IGF2 mRNA-binding protein 2: Biological function and putative role in type 2 diabetes. J Mol Endocrinol 43: 187-195, 2009.

4. Nielsen J, Christiansen J, Lykke-Andersen J, Johnsen AH, Wewer UM and Nielsen FC: A family of insulin-like growth factor II mRNA-binding proteins represses translation in late development. Mol Cell Biol 19: 1262-1270, 1999.

5. Sun XJ, Rothenberg P, Kahn CR, Backer JM, Araki E, Wilden PA, Cahill DA, Goldstein BJ and White MF: Structure of the insulin receptor substrate IRS-1 defines a unique signal transduction protein. Nature 352: 73-77, 1991.

6. Nandi A, Kitamura Y, Kahn CR and Accili D: Mouse models of insulin resistance. Physiol Rev 84: 623-647, 2004.

7. Sesti G, Federici M, Hribal ML, Lauro D, Sbraccia P and Lauro R: Defects of the insulin receptor substrate (IRS) system in human metabolic disorders. FASEB J 15: 2099-2111, 2001.

8. Saxena R, Hivert MF, Langenberg C, Tanaka T, Pankow JS, Vollenweider P, Lyssenko V, Bouatia-Naji N, Dupuis J, Jackson AU, et al; GIANT consortium; MAGIC investigators: Genetic variation in GIPR influences the glucose and insulin responses to an oral glucose challenge. Nat Genet 42: 142-148, 2010.

9. Irwin N and Flatt PR: Therapeutic potential for GIP receptor agonists and antagonists. Best Pract Res Clin Endocrinol Metab 23: 499-512, 2009

10. Yi F, Brubaker PL and Jin T: TCF-4 mediates cell type-specific regulation of proglucagon gene expression by beta-catenin and glycogen synthase kinase-3beta. J Biol Chem 280: 1457-1464, 2005.

11. Villareal DT, Robertson H, Bell GI, Patterson BW, Tran H, Wice B and Polonsky KS: TCF7L2 variant rs7903146 affects the risk of type 2 diabetes by modulating incretin action. Diabetes 59: 479-485, 2010

12. American Diabetes Association: Diagnosis and classification of diabetes mellitus. Diabetes Care 33 (Suppl 1): S62-S69, 2010

13. Dupont WD and Plummer WD Jr: Power and sample size calculations. A review and computer program. Control Clin Trials 11: 116-128, 1990.

14. Chistiakov DA, Nikitin AG, Smetanina SA, Bel'chikova LN, Suplotova LA, Shestakova MV and Nosikov VV: The rs11705701 $\mathrm{G}>\mathrm{A}$ polymorphism of IGF2BP2 is associated with IGF2BP2 mRNA and protein levels in the visceral adipose tissue - a link to type 2 diabetes susceptibility. Rev Diabet Stud 9: 112-122, 2012.

15. Li X, Allayee H, Xiang AH, Trigo E, Hartiala J, Lawrence JM, Buchanan TA and Watanabe RM: Variation in IGF2BP2 interacts with adiposity to alter insulin sensitivity in Mexican Americans. Obesity (Silver Spring) 17: 729-736, 2009.

16. Diabetes Genetics Initiative of Broad Institute of Harvard and MIT, Lund University, and Novartis Institutes of BioMedical Research; Saxena R, Voight BF, Lyssenko V, Burtt NP, de Bakker PI, Chen H, Roix JJ, Kathiresan S, Hirschhorn JN, et al: Genome-wide association analysis identifies loci for type 2 diabetes and triglyceride levels. Science 316: 1331-1336, 2007.
17. Chang Y-C, Liu P-H, Yu Y-H, Kuo SS, Chang TJ, Jiang YD, Nong JY, Hwang JJ and Chuang LM: Validation of type 2 diabetes risk variants identified by genome-wide association studies in Han Chinese population: A replication study and meta-analysis. PLoS One 9: e95045, 2014

18. Lasram K, Ben Halim N, Benrahma H, Mediene-Benchekor S, Arfa I, Hsouna S, Kefi R, Jamoussi H, Ben Ammar S, Bahri S, et al: Contribution of CDKAL1 rs7756992 and IGF2BP2 rs4402960 polymorphisms in type 2 diabetes, diabetic complications, obesity risk and hypertension in the Tunisian population. J Diabetes 7: $102-113,2015$

19. Al-Sinani S, Woodhouse N, Al-Mamari A, Al-Shafie O, Al-Shafaee M, Al-Yahyaee S, Hassan M, Jaju D, Al-Hashmi K, Al-Abri M, et al: Association of gene variants with susceptibility to type 2 diabetes among Omanis. World J Diabetes 6: 358-366, 2015.

20. Wu J, Wu J, Zhou Y, Zou H, Guo S, Liu J, Lu L and Xu H: Quantitative assessment of the variation in IGF2BP2 gene and type 2 diabetes risk. Acta Diabetologica 49 (Suppl 1): S87-S97, 2012

21. Sonestedt E, Lyssenko V, Ericson U, Gullberg B, Wirfält E, Groop L and Orho-Melander M: Genetic variation in the glucose-dependent insulinotropic polypeptide receptor modifies the association between carbohydrate and fat intake and risk of type 2 diabetes in the Malmo Diet and Cancer cohort. J Clin Endocrinol Metab 97: E810-E818, 2012.

22. Saxena R, Hivert MF, Langenberg C, Tanaka T, Pankow JS, Vollenweider P, Lyssenko V, Bouatia-Naji N, Dupuis J, Jackson AU, et al: Genetic variation in GIPR influences the glucose and insulin responses to an oral glucose challenge. Nat Genet 42: 142-148, 2010

23. Voight BF, Scott LJ, Steinthorsdottir V, Morris AP, Dina C, Welch RP, Zeggini E, Huth C, Aulchenko YS, Thorleifsson $\mathrm{G}$, et al: Twelve type 2 diabetes susceptibility loci identified through large-scale association analysis. Nat Genet 42: 579-589, 2010.

24. Haupt A, Thamer C, Heni M, Ketterer C, Machann J, Schick F, Machicao F, Stefan N, Claussen CD, Häring HU, et al: Gene variants of TCF7L2 influence weight loss and body composition during lifestyle intervention in a population at risk for type 2 diabetes. Diabetes 59: 747-750, 2010

25. Dou H, Ma E, Yin L, Jin Y and Wang H: The association between gene polymorphism of TCF7L2 and type 2 diabetes in Chinese Han population: A meta-analysis. PLOS One 8: e59495, 2013.

26. Lou XY, Chen GB, Yan L, Ma JZ, Zhu J, Elston RC and Li MD: A generalized combinatorial approach for detecting gene-by-gene and gene-by-environment interactions with application to nicotine dependence. Am J Hum Genet 80: 1125-1137, 2007. 